\title{
VIABILIDADE PARA UTILIZAÇÃO DE CINZA DE CALDEIRA INDUSTRIAL NA DOSAGEM DE CONCRETO ESTRUTURAL
}

\section{ARTIGO ORIGINAL}

JUSTINO, Lucas Diego de Souza ${ }^{1}$

JUSTINO, Lucas Diego de Souza. Viabilidade para utilização de cinza de caldeira industrial na dosagem de concreto estrutural. Revista Científica Multidisciplinar Núcleo do Conhecimento. Ano 06, Ed. 09, Vol. 02, pp. 81-97. Setembro de 2021. ISSN: 2448-0959, Link

de acesso: https://www.nucleodoconhecimento.com.br/engenharia-civil/concreto-estrutural, DOI: 10.32749/nucleodoconhecimento.com.br/engenharia-civil/concreto-estrutural

\section{RESUMO}

A industrialização e o crescimento populacional acelerado, geram efeitos colaterais sobre diversos aspectos sociais, sendo a questão ambiental preocupante devido aos impactos causados pela evolução social. A gestão de resíduos industriais é um grande desafio que envolve tanto controle de sua geração, quanto da destinação adequada, garantindo sustentabilidade ambiental. O resíduo de cinza de caldeira é encontrado em abundância nas fábricas que utilizam esse equipamento para geração de vapor. Essa abundância ocorre pela falta de local para destinação adequada ou reutilização do resíduo. Tendo em vista esse cenário, o presente artigo teve como questão norteadora: Seria possível utilizar esse resíduo na produção de concreto estrutural? O objetivo do estudo foi classificar o resíduo definindo sua possível forma de utilização na dosagem de concreto e realizar dosagens experimentais com a utilização da cinza de caldeira industrial para avaliar suas possíveis contribuições técnicas para propriedades básicas do concreto. Para isto, foi realizada a coleta de amostras cedida por uma indústria instalada no município de Uberlândia, estado de Minas Gerais, atuante em diversos setores como

\footnotetext{
${ }^{1}$ Graduado em Engenharia Civil. ORCID: 0000-0003-2630-8866
}

RC: 96589

Disponível em: https://www.nucleodoconhecimento.com.br/engenhariacivil/concreto-estrutural 
agricultura, nutrição animal, farmacêutico e outros. A classificação da cinza de caldeira foi realizada aplicando-se os procedimentos e parâmetros normativos brasileiros utilizados para classificação de aglomerantes e agregados para concreto. Considerando sua curva granulométrica e densidade, classificou-se o resíduo como agregado leve e muito fino, sendo assim, adotou-se a metodologia de substituição parcial do agregado fino por cinza de caldeira. Verificou-se que houve redução da trabalhabilidade do concreto no estado fresco proporcionalmente ao teor de resíduo utilizado. Portanto, é necessária a utilização de aditivos superplastificantes nesses casos, para manutenção da trabalhabilidade esperada. Notou-se redução da densidade do concreto quando utilizado o resíduo, considerando como necessária a atenção a essa propriedade do concreto com relação ao teor utilizado do resíduo na dosagem. Observou-se, também, ao comparar as dosagens com a utilização do resíduo à dosagem padrão, que houve redução de resistência a compressão. Porém, não houve grande variação de resistência a compressão entre as dosagens com diferentes teores de substituição utilizados. Concluiu-se, portanto, considerando os teores utilizados nesse estudo, como viável a utilização desse resíduo na produção de concreto estrutural.

Palavras-chave: Concreto, Biomassa, Cinza de Caldeira Industrial.

\section{INTRODUÇÃO}

A Revolução Industrial iniciada na Inglaterra no século XVIII a partir da criação da máquina a vapor pelo engenheiro escocês James Watt, impulsionou a industrialização britânica de modo a transformar o sistema produtivo. Esse período segundo Cavalcante (2011) "foi o precursor do capitalismo, ou seja, a passagem do capitalismo comercial para o capitalismo industrial". Isso significa que, nesse contexto, o regime de manufatura, até então utilizado, é substituído pelo regime de maquino fatura, resultando em processos produtivos muito mais ágeis e capazes de colocar em prática a produção em massa, garantindo maior oferta de produtos e baixos custos de produção, comparando-se ao cenário anterior. 
As transformações ocorridas no período da Revolução Industrial se expandiram no âmbito global e acompanharam a evolução da sociedade ao longo do tempo, modernizando e aperfeiçoando as práticas produtivas no decorrer dos anos. Porém, com o avanço do processo de industrialização, o crescimento populacional mundial e consequentemente a alta demanda por produtos, o consumo de recursos naturais cresce proporcionalmente a essa demanda, visto que esses recursos servem como matéria prima para os processos de fabricação.

O processo acelerado de crescimento gera, portanto, como efeitos colaterais, os impactos ambientais causados pela exploração de recursos naturais, sem a devida gestão voltada a manutenção e conservação do meio ambiente. "A exploração dos recursos naturais se tornou predatória em prol da obtenção de capital" (GANZALA, 2018).

Os reflexos negativos da industrialização ao longo dos séculos $X X$ e $X X I$ relacionados ao meio ambiente, não estão ligados apenas ao consumo não sustentável dos recursos naturais envolvidos nos processos produtivos, mas também a poluição da água, do solo e do ar, causada pelos rejeitos ou resíduos gerados pelos processos industriais. Essa realidade é constatada tanto nos países desenvolvidos como naqueles em desenvolvimento.

Diversos processos industriais utilizam equipamentos chamados caldeiras para geração de vapor no processo produtivo de diversas indústrias sucroalcooleiras, fábricas de secagem e parboilização de grãos, frigoríficos, indústria metalúrgica, têxtil e no setor de geração de energia. O tipo mais comum de caldeira utilizado atualmente é a chamada caldeira a biomassa. Essas caldeiras utilizam como material de combustão as diferentes formas de biomassa como: pinus, eucalipto, casca de arroz e bagaço de cana. Após a queima da biomassa, é gerada a cinza de caldeira como resíduo, portanto a cinza de caldeira consiste na parte resistente à queima, presente na composição da biomassa utilizada como combustível nas caldeiras industriais. 
As indústrias que utilizam as caldeiras, visando a eficiência energética e o fator econômico, aplicam controles de processos de queima de biomassa, que reduzem ao máximo a geração desse tipo de resíduo. Porém, a geração do resíduo é inevitável nesse processo. Portanto, a disponibilidade desse resíduo se torna abundante. Nessas indústrias, acumulam-se grandes depósitos desse material devido à falta de alternativas para destinação ou reaproveitamento do mesmo. Esses depósitos ocupam grandes espaços físicos nas plantas de produção, que poderiam ser mais bem utilizados, considerando a atividade fim da indústria em questão.

No cenário encontrado de alta disponibilidade do resíduo cinza de caldeira e a falta de local para descarte adequado ou atividade para reaproveitamento do resíduo, surge, então, a questão norteadora para o desenvolvimento desse estudo: seria possível a utilização desse resíduo na produção de concretos estruturais? Considerando o ritmo acelerado do setor da construção civil e sua busca por inovações, o resíduo gerado poderia ser reutilizado nesse segmento como alternativa sustentável, com a possibilidade de promover benefícios técnicos e econômicos tanto para a indústria geradora do resíduo, quanto para as empresas produtoras de concreto.

A contribuição ambiental é a conquista principal e a mais significativa com a utilização do resíduo de cinza de caldeiras industriais na produção de concreto estrutural, pois haveria dupla contribuição ambiental ao evitar o descarte do resíduo no meio ambiente, e, se verificada a possibilidade de sua aplicação como substituição parcial de agregados naturais, evitaria a extração de parte desses recursos naturais, que cada vez se encontram mais escassos.

As empresas produtoras de concreto têm por característica utilizar matérias primas brutas, ou seja, sem a necessidade de grandes processos de beneficiamento, como é o caso das areias naturais, que são extraídas dos rios ou jazidas, e requerem beneficiamentos simples como peneiramento para retirada de impurezas e classificação granulométrica. Portanto, a utilização do resíduo na produção de 
concreto tem contribuição econômica tanto para a indústria geradora do resíduo, que disponibiliza o resíduo sem necessidade de grandes processos de beneficiamento, quanto para as empresas produtoras de concreto, que se beneficiariam da alta disponibilidade do resíduo e seu baixo custo, sendo utilizado como matéria prima em sua produção.

O objetivo geral desse estudo é realizar a classificação preliminar do resíduo de cinzas de caldeira industrial, definir sua possível forma de utilização na dosagem de concreto, realizar dosagens experimentais para verificar desempenho de propriedades básicas do concreto dosado com a utilização de cinza de cadeira, avaliando possíveis contribuições técnicas e, finalmente, concluir a viabilidade da utilização desse resíduo para dosagem de concretos estruturais.

\section{METODOLOGIA}

A concepção inicial da possibilidade de tornar-se viável a utilização da cinza de caldeira para produção de concreto surge da idéia de que, originalmente, utilizava-se na produção de concreto apenas três materiais básicos: cimento, agregado e água. Porém, para melhor desempenho tanto no estado fresco, quanto no estado endurecido, iniciou-se a utilização de aditivos químicos. Após algum tempo, introduziu-se nesse contexto a utilização de materiais cimentícios de natureza orgânica como adições à mistura do concreto como escórias granuladas de alto forno, pozolanas, fumo de sílica e cinzas volantes.

As razões iniciais para se usarem estes materiais usualmente eram econômicas: eles custavam menos que o cimento Portland, muitas vezes por que existiam em depósitos naturais, necessitando pouco ou nenhum processamento, outras vezes porque eram subprodutos ou rejeitos de processos industriais (NEVILLE, 1997, p. 81).

"As cinzas volantes são resultantes de caldeiras no processo de queima de carvão em que parte da matéria mineral aglomera formando cinza de grelha, mas a maior parte dela é arrastada pela corrente de exaustão do gás, que é chamada de cinza volante" (MEHTA; MONTEIRO, 1994). 
Esse estudo foi realizado no mês de Abril do ano de 2021, através de pesquisas por inovações para o segmento de produção de concreto na região do município de Uberlândia, estado de Minas Gerais, onde observou-se grande quantidade de indústrias instaladas nessa localidade, as quais utilizavam as caldeiras como meio de geração de vapor em seus processos produtivos e, portanto, havia grande disponibilidade de cinzas de caldeira, bem como a grande necessidade de adequada destinação ambiental ou reaproveitamento do resíduo.

\subsection{AMOSTRA E CARACTERIZAÇÃO DA CINZA}

A amostra do material utilizado nesse estudo foi cedida por grande indústria instalada no município de Uberlândia, estado de Minas Gerais, atuante em diversos setores como agricultura, nutrição animal, farmacêutico e outros. As cinzas resultantes do processo de queima da biomassa de eucalipto são misturadas com água para evitar dispersão atmosférica, e conduzida em processo de decantação, onde foi realizada a coleta da amostra. Portanto, o material coletado apresenta alto teor de umidade, verificado visualmente pela água livre presente superficialmente na amostra coletada, além da água absorvida pelo próprio material.

Após a coleta da amostra e sua condução ao laboratório de materiais, foi realizado o processo de secagem do material para dar início a sua caracterização básica. Devido ao alto teor de umidade observado na amostra, foi necessário iniciar o processo de secagem espalhando-se o material ao ar livre sobre forro plástico, evitando contaminações e dispersões do mesmo. Após a secagem parcial ao ar livre, o material foi levado a estufa para término do processo de secagem.

Foi determinado o índice de finura pela peneira número 200, conforme NBR 11579 ABNT (2012). Durante a realização desse ensaio, observou-se que no material retido na peneira número 200 , a maior parte constituiu-se de material fino, porém notou-se a presença de partículas com dimensões granulométricas maiores, porém em pequena proporção. O índice de finura encontrado para o material foi de $46 \%$. 
Esse índice foi considerado elevado, comparando-se ao cimento Portland, que tem esse índice máximo de 10\%, estabelecido pela NBR 16697 (ABNT, 2018).

Realizou-se a determinação da massa específica aparente, conforme NM 52 ABNT (2009). A cinza apresentou massa específica aparente de $0,26 \mathrm{~g} / \mathrm{cm}^{3}$. Para Bauer (2008), os agregados podem ser classificados segundo seu peso específico. Portando, a cinza se classificou, nesse aspecto, como agregado leve, sendo o peso específico encontrado equivalente ao peso específico de agregados leves conhecidos, como exemplo de agregado leve a vermiculita, que possui peso específico de $0,3 \mathrm{~g} / \mathrm{cm}^{3}$.

A caracterização granulométrica foi realizada conforme NBR NM 248 ABNT (2003). A cinza apresentou distribuição granulométrica conforme Tabela 1, módulo de finura de 0,74 e dimensão máxima de $1,2 \mathrm{~mm}$.

Tabela 1 - Distribuição Granulométrica Cinza de Caldeira

\begin{tabular}{|l|l|l|}
\hline $\begin{array}{l}\text { Peneira } \\
\text { (mm) }\end{array}$ & Retido (\%) & Acumulado (\%) \\
\hline $\mathbf{2 , 4}$ & 0,80 & 0,80 \\
\hline $\mathbf{1 , 2}$ & 2,47 & 3,27 \\
\hline $\mathbf{0 , 6}$ & 5,74 & 9,01 \\
\hline $\mathbf{0 , 3}$ & 12,23 & 21,24 \\
\hline $\mathbf{0 , 1 5}$ & 18,43 & 39,67 \\
\hline Fundo & 60,33 & $\star \star \star$ \\
\hline
\end{tabular}

Fonte: Autor (2021).

Com base nas características básicas verificadas, buscou-se atribuir classificação inicial da cinza para definir-se sua forma de aplicação em dosagens de concreto. Foram cogitadas inicialmente duas possibilidades descritas a seguir. 
A primeira possibilidade de utilização da cinza seria incorporá-la à dosagem de concreto como adição, partindo como referência as adições de materiais como exemplo da sílica ativa, muito utilizada na produção de concretos de alto desempenho e para potencializar propriedades específicas do concreto, como resistências mecânicas, principalmente. Porém, pelo perfil verificado da cinza na determinação do seu índice de finura e distribuição granulométrica, foi descartada essa possibilidade devido a incompatibilidade de suas características com esse tipo de adição.

Como segunda possibilidade de utilização da cinza foi verificada sua possível introdução como substituição de agregados na dosagem de concreto. Observou-se os resultados obtidos com relação ao peso específico e, conforme já relatado, enquadrou-se como agregado leve. Outra característica analisada, considerando essa possibilidade de utilização foi a classificação da cinza com relação a faixa granulométrica em que se enquadrou, com base na Tabela 2 .

Tabela 2 - Classificação de Areias por Faixas Granulométricas

\begin{tabular}{|c|c|c|c|c|}
\hline $\begin{array}{l}\text { Porcentagens } \\
\text { Retidas }\end{array}$ & & & & \\
\hline Peneiras (mm) & $\begin{array}{l}\text { Faixa } 1 \text { - Muito } \\
\text { Fina }\end{array}$ & $\begin{array}{l}\text { Faixa } 2- \\
\text { Fina }\end{array}$ & $\begin{array}{l}\text { Faixa } 3- \\
\text { Média }\end{array}$ & $\begin{array}{l}\text { Faixa } 4 \quad- \\
\text { Grossa }\end{array}$ \\
\hline 6,3 & 0 a 3 & 0 a 7 & 0 a 7 & 0 a 7 \\
\hline 4,8 & 0 a 5 & 0 a 10 & 0 a 11 & 0 a 12 \\
\hline 2,4 & 0 a 5 & 0 a 15 & 0 a 25 & 5 a 40 \\
\hline 1,2 & 0 a 10 & 0 a 25 & 10 a 45 & 30 a 70 \\
\hline 0,6 & 0 a 20 & 21 a 40 & 41 a 65 & 66 a 85 \\
\hline 0,3 & 50 a 85 & 60 a 88 & 70 a 92 & 80 a 95 \\
\hline 0,15 & 85 a 100 & 90 a 100 & 90 a100 & 90 a 1 \\
\hline
\end{tabular}

Fonte: Bauer (2008). 
A distribuição granulométrica da cinza apresentada na tabela 1, não se enquadrou totalmente em nenhuma das faixas de classificação descritas na tabela 2. Notou-se, porém, características semelhantes a distribuição classificada como faixa 1 - Muito Fina, enquadrando-se nessa faixa as porcentagens retidas nas peneiras com abertura 2,4 mm, 1,2 $\mathrm{mm}$ e 0,6 $\mathrm{mm}$. Nas demais peneiras as porcentagens retidas se mantiveram abaixo das especificadas na tabela 2. Foi observada grande concentração de material no fundo da série de peneiras, ou seja, material passante na peneira com abertura $0,15 \mathrm{~mm}$.

Verificou-se, portanto, que a cinza apresentou distribuição granulométrica muito próxima a faixa 1 - Muito Fina, porém com percentual significativo de material mais fino do que previsto nessa faixa granulométrica, ou seja, tendendo-se para uma faixa anterior, caso houvesse.

O módulo de finura de 0,74 , obtido pela caracterização granulométrica da cinza, conforme já relatado, reforçou a classificação da cinza em faixa anterior a faixa 1 Muito Fina, visto que o módulo de finura mínimo para classificação nessa faixa seria de 1,35 (BAUER, 2008).

Devido a incompatibilidade da cinza com o índice de finura de adições tradicionalmente utilizadas e sua classificação parcial como agregado muito fino, optou-se, portanto, pelo estudo da possibilidade de substituição de agregados muito finos por cinza na dosagem de concreto.

\subsection{TRAÇO PADRÃO E TEORES DE SUBSTITUIÇÃO}

A definição do traço a ser utilizado como padrão baseou-se nas características da cinza, determinadas anteriormente. O traço padrão deveria conter em sua composição o agregado classificado como muito fino, o qual seria substituído pela cinza.

O aumento do consumo de água na dosagem em função da adição de cinza foi um ponto de atenção na definição do traço padrão, pois levando-se em consideração o

RC: 96589

Disponível em: https://www.nucleodoconhecimento.com.br/engenhariacivil/concreto-estrutural 
alerta de Neville (1997) "a cinza de palha de arroz tem formas complexas, conforme planta de origem e, portanto, demandam muita água.", observou-se o tempo demandado para secagem da amostra da cinza de caldeira e cogitou-se que devido a sua origem e superfície específica, possivelmente a adição da cinza aumentaria o consumo de água na dosagem, em relação a dosagem padrão.

Para combater o aumento do consumo de água nas dosagens com adição de cinzas, é recomendado por Neville (1997) a utilização de aditivos superplastificantes para se atingir a trabalhabilidade esperada. Portanto, optou-se pela definição do traço padrão com a utilização desse tipo de aditivo.

O traço padrão foi adotado com resistência à compressão requerida de $25 \mathrm{MPa}$ e espalhamento entre 600 e $650 \mathrm{~mm}$, determinado conforme NBR 15823-2 ABNT (2017). Foram encontradas as seguintes proporções para o traço unitário em massa: $1: 0,59: 2,21: 1,11: 2,60$, com relação a/c igual a 0,58 , obteve-se o quantitativo para mistura conforme Tabela 3.

Tabela 3 - Traço Padrão 25,0 MPa Espalhamento 600 a 650 mm

\begin{tabular}{|l|l|l|}
\hline Cimento & $\mathbf{1 0}$ & $\mathbf{K g}$ \\
\hline Areia Muito Fina & 5,88 & $\mathrm{Kg}$ \\
\hline Areia Média & 22,10 & $\mathrm{Kg}$ \\
\hline Brita 0 & 11,12 & $\mathrm{Kg}$ \\
\hline Brita 1 & 25,96 & $\mathrm{Kg}$ \\
\hline Aditivo Plastificante & 0,035 & $\mathrm{Lt}$ \\
\hline $\begin{array}{l}\text { Aditivo } \\
\text { Superplastificante }\end{array}$ & 0,10 & $\mathrm{Lt}$ \\
\hline Água & & \\
\hline
\end{tabular}

Fonte: Autor (2021).

O agregado denominado como "areia muito fina" na Tabela 3 foi o agregado adotado como substituível por cinza de caldeira. $O$ agregado apresentou em sua distribuição

RC: 96589

Disponível em: https://www.nucleodoconhecimento.com.br/engenhariacivil/concreto-estrutural 
granulométrica, módulo de finura de 1,42, classificando-se na faixa granulométrica 1, que comporta agregados com módulo de finura entre 1,35 e 2,25. Portanto foi classificado como agregado muito fino (BAUER, 2008).

A substituição do agregado muito fino por cinza foi realizado de forma parcial, ou seja, adotando-se teores de substituição aleatórios e progressivos, a fim de provocar a observação das possíveis influências causadas pela substituição do agregado por cinza de caldeira. Como ponto de partida, foram adotados teores de substituição de $10 \%, 20 \%$ e $30 \%$ sobre a massa de agregado muito fino presente na dosagem do traço padrão já apresentada na Tabela 3 .

A Tabela 4 apresenta os traços unitários em massa adotados para cada teor de substituição estabelecidos.

Tabela 4 - Traços unitários em massa adotados de acordo com o teor de substituição do agregado muito fino por cinza de caldeira

\begin{tabular}{|l|ll|}
\hline $\begin{array}{l}\text { Teor de substituição do agregado por } \\
\text { cinza }\end{array}$ & Traço unitário em massa \\
\hline $\mathbf{1 0} \%$ & $1: 0,06: 0,53: 2,21: 1,11: 2,60 \quad \mathrm{a} / \mathrm{c}=$ \\
& 0,58 & \\
\hline $\mathbf{2 0} \%$ & $1: 0,12: 0,47: 2,21: 1,11: 2,60 \quad \mathrm{a} / \mathrm{c}=$ \\
& 0,58 & \\
\hline $\mathbf{3 0} \%$ & $1: 0,18: 0,41: 2,21: 1,11: 2,60 \quad \mathrm{a} / \mathrm{c}=$ \\
& 0,58 & \\
\hline
\end{tabular}

Fonte: Autor (2021).

\subsection{DOSAGENS EXPERIMENTAIS E AVALIAÇÕES REALIZADAS}

Foram realizadas as dosagens experimentais em laboratório utilizando betoneira elétrica estacionária. Primeiramente foi realizada a dosagem do traço padrão 
apresentado na Tabela 3, e em seguida dos demais traços com os respectivos teores de substituição adotados, apresentados na Tabela 4.

Como critério de avaliação principal, adotou-se as possíveis influências da introdução da cinza de caldeira nas dosagens com relação as propriedades: trabalhabilidade do concreto no estado fresco, densidade e resistência à compressão.

Para avaliação da influência da introdução da cinza na dosagem com relação a trabalhabilidade do concreto no estado fresco, foi realizado em todas as dosagens o ensaio para determinação da consistência inicial pelo abatimento do tronco de cone, conforme NBR 16889 ABNT (2020). A consistência inicial adotada como padrão foi entre $40 \mathrm{~mm}$ e $60 \mathrm{~mm}$. Após alcançar a consistência inicial, o aditivo superplastificante foi adicionado às dosagens com o objetivo de aumentar a trabalhabilidade e alcançar o espalhamento entre 600 e $650 \mathrm{~mm}$, que foi determinado em todas as dosagens conforme NBR 15823-2 ABNT (2017).

Com relação a densidade, foi determinada conforme NBR 9833 ABNT (2008).

A avaliação da resistência a compressão foi realizada através de moldagens de corpos de prova cilíndricos com dimensões de 10x20mm, conforme NBR 5738 ABNT (2016). Foram submetidos dois exemplares de cada série ao ensaio para determinação da resistência à compressão axial nas idades de 7 dias, 14 dias e 28 dias, conforme NBR 5739 ABNT (2018).

\subsection{RESULTADOS E DISCUSSÕES}

$\mathrm{Na}$ dosagem do traço padrão, observou-se que a água prevista no traço foi suficiente para o alcance da consistência inicial, pois obteve-se índice de consistência inicial de 52mm. Sendo assim, foi introduzido o aditivo superplastificante a mistura e estabeleceu-se o tempo de mistura de 8 minutos após a dosagem do aditivo superplastificante. Esse tempo de mistura é o tempo médio determinado pelo fabricante para contemplar o efeito completo do aditivo. Após o

RC: 96589

Disponível em: https://www.nucleodoconhecimento.com.br/engenhariacivil/concreto-estrutural 
tempo de mistura, determinou-se o espalhamento e obteve-se $620 \mathrm{~mm}$ como resultado, ou seja, dentro dos parâmetros estabelecidos anteriormente.

Após a dosagem do traço padrão, realizou-se a dosagem do traço com teor de substituição de $10 \%$ do agregado muito fino pela cinza de caldeira. Nessa dosagem, utilizando-se a mesma quantidade de água em relação ao traço padrão, obteve-se índice de consistência inicial de $49 \mathrm{~mm}$. Notou-se, portanto, que a introdução da cinza causou uma leve queda de consistência inicial do concreto. Porém, estando ainda dentro dos parâmetros estabelecidos incialmente, realizou-se a dosagem do aditivo superplastificante e respeitando-se o tempo padrão de 8 minutos para mistura, determinou-se posteriormente o espalhamento e obteve-se $600 \mathrm{~mm}$ de abertura.

Em sequência, foi realizada a dosagem do traço com teor de substituição de $20 \%$ do agregado muito fino pela cinza de caldeira. Com a mesma quantidade de água utilizada nas dosagens anteriores, obteve-se índice de consistência inicial de $50 \mathrm{~mm}$. Com a dosagem do aditivo superplastificante e término do tempo padrão de mistura, obteve-se espalhamento de $600 \mathrm{~mm}$ de abertura, ou seja, comportamento muito semelhante ao da dosagem anterior, com teor de substituição de $10 \%$ do agregado muito fino pela cinza de caldeira.

Por fim, realizou-se a dosagem do traço com teor de substituição de $30 \%$ do agregado muito fino pela cinza de caldeira. Mantendo-se a quantidade de água das dosagens anteriores, obteve-se o índice de consistência inicial de $38 \mathrm{~mm}$, ou seja, abaixo do parâmetro inicial estabelecido. Nesse caso, observou-se que a introdução da cinza na mistura, interferiu na consistência inicial conforme alertado por Neville (1997), porém optou-se pela sequência da dosagem pelo fato de o índice de consistência inicial obtido estar muito próximo ao limite inferior estabelecido, que foi de $40 \mathrm{~mm}$. Após a dosagem do aditivo superplastificante e término do tempo de mistura, obteve-se espalhamento de $560 \mathrm{~mm}$. Portanto abaixo do parâmetro inicialmente. 
No caso específico da dosagem com teor de substituição de $30 \%$ do agregado muito fino pela cinza de caldeira, optou-se por aumentar a dosagem do aditivo superplastificante com 0 objetivo de alcançar o espelhamento mínimo prédeterminado. Portanto, elevou-se a dosagem do aditivo superplastificante de $1 \%$ para $1,5 \%$ sobre o peso de cimento. Após esse acréscimo de aditivo a mistura e respeitado novamente o tempo de mistura para ação total do aditivo, obteve-se o espalhamento de $610 \mathrm{~mm}$, ou seja, enquadrando-se nos parâmetros préestabelecidos. A trabalhabilidade é propriedade importantíssima, pois "uma mistura de concreto que não possa ser lançada facilmente ou adensada em sua totalidade não fornecerá as características de resistência e durabilidade esperadas" (MEHTA; MONTEIRO, 1994).

As densidades encontradas conforme NBR 9833 ABNT (2018) são apresentadas na Tabela 5.

Tabela 5 - Densidades determinadas

\begin{tabular}{|c|c|}
\hline Identificação da série & Densidade $\left(\mathrm{kg} / \mathrm{m}^{3}\right)$ \\
\hline Traço padrão & 2335 \\
\hline $\begin{array}{llll}\text { Traço com } 10 \% \text { de } \\
\text { Cinza }\end{array}$ & 2078 \\
\hline $\begin{array}{l}\text { Traço com } 20 \% \text { de } \\
\text { Cinza }\end{array}$ & 2070 \\
\hline $\begin{array}{l}\text { Traço com } 30 \% \text { de } \\
\text { Cinza }\end{array}$ & 2066 \\
\hline
\end{tabular}

Fonte: Autor (2021).

Observou-se que houve queda de $11 \%$ de densidade, comparando-se o traço padrão ao traço com teor de substituição de $10 \%$ do agregado muito fino pela cinza de caldeira. Para os traços seguintes, com teores de substituição de $20 \%$ e $30 \%$, as quedas de densidade registradas foram da ordem de $0,4 \%$ e $0,2 \%$, respectivamente, 
comparando-se o traço analisado ao traço anterior ao mesmo, considerando a ordem gradual e progressiva dos teores de substituição do agregado muito fino pela cinza de caldeira.

Os resultados encontrados nos ensaios para determinação de resistência à compressão axial são apresentados na Tabela 6.

Tabela 6 - Resistência a Compressão (MPa) por série

\begin{tabular}{|c|c|c|c|c|}
\hline $\begin{array}{l}\text { Série/Idade/Resistência } \\
\text { (MPa) }\end{array}$ & Compressão & 7 dias & 14 dias & 28 dias \\
\hline Traço padrão & & 18,1 & 21,0 & 30,3 \\
\hline Traço com $10 \%$ de Cinza & & 14,6 & 18,0 & 19,6 \\
\hline Traço com $20 \%$ de Cinza & & 15,2 & 18,3 & 20,2 \\
\hline Traço com $30 \%$ de Cinza & & 14,6 & 18,5 & 19,8 \\
\hline
\end{tabular}

Fonte: Autor (2021).

Verificou-se pelos resultados obtidos que as dosagens com a utilização da cinza de caldeira apresentaram resistências a compressão menores que o traço padrão adotado em todas as idades ensaiadas. A média de queda de resistência a compressão dos traços com utilização de cinza de caldeira em relação ao traço padrão se apresentou conforme apresentado na Tabela 7.

Tabela 7 - Percentual de queda de resistência a compressão em relação ao traço padrão

\begin{tabular}{|llll|l|l|l|}
\hline \multicolumn{2}{|l|}{ Traço/ldade } & & & $\mathbf{7}$ dias & $\mathbf{1 4}$ dias & $\mathbf{2 8}$ dias \\
\hline $\begin{array}{l}\text { Traço } \\
\text { Cinza }\end{array}$ & com & $\mathbf{1 0 \%}$ & de & $19 \%$ & $14 \%$ & $35 \%$ \\
\hline $\begin{array}{l}\text { Traço } \\
\text { Cinza }\end{array}$ & $\mathbf{2 0 \%}$ & de & $16 \%$ & $13 \%$ & $33 \%$ \\
\hline Traço com & $\mathbf{3 0} \%$ & de & $19 \%$ & $12 \%$ & $35 \%$ \\
\hline
\end{tabular}

RC: 96589

Disponível em: https://www.nucleodoconhecimento.com.br/engenhariacivil/concreto-estrutural 


\section{Cinza}

Fonte: Autor (2021).

Observou-se que em todos os traços com a utilização da cinza, o percentual de queda de resistência a compressão em relação ao traço padrão se comportou de forma semelhante independente do teor de substituição utilizado.

Com relação a coloração dos concretos dosados, verificou-se que tanto no estado fresco, como no estado endurecido, o teor de substituição de agregado muito fino por cinza de caldeira influenciou de forma evidente nesse aspecto visual, pois devido a coloração da cinza de caldeira ser semelhante a do cimento Portland, os concretos com teores maiores de utilização da cinza se apresentaram visualmente como concretos com maior consumo de cimento, ou seja, com coloração mais escura quanto maior o teor de substituição adotado.

\section{CONSIDERAÇÕES FINAIS}

A cinza de caldeira industrial classificou-se como leve e com faixa granulométrica ligeiramente abaixo da faixa muito fina, ambas as classificações são aplicadas para agregados, portanto concluiu-se sua aplicação como agregado leve e muito fino.

Com aumento do teor de substituição do agregado pela cinza de caldeira industrial na dosagem, houve influência na trabalhabilidade do concreto, observada pela redução do abatimento inicial e no espalhamento final. Portanto, concluiu-se a importância em se adotar o método de substituição parcial do agregado para utilização da cinza de caldeira industrial, visto que se adotada a substituição total do agregado, possivelmente haveria impacto ainda maior nessa propriedade do concreto no estado fresco.

Concluiu-se a importante contribuição do aditivo superplastificante nas dosagens com a utilização de cinza de caldeira industrial, com o objetivo de compensar a perda de trabalhabilidade causada pela utilização da cinza de caldeira. Entendeu-se

RC: 96589

Disponível em: https://www.nucleodoconhecimento.com.br/engenhariacivil/concreto-estrutural 
que com aditivos plastificantes, não seria possível alcançar trabalhabilidade satisfatória nos concretos dosados com a cinza de caldeira industrial devido à natureza da cinza e sua grande superfície específica, que resulta em maior consumo de água nas dosagens.

Com relação a densidade, concluiu-se que com a substituição do agregado por cinza de caldeira industrial, houve um decréscimo de densidade relacionado ao aumento do teor de substituição, ou seja, quanto maior o teor de substituição do agregado pela cinza de caldeira industrial, menor a densidade verificada. Considerou-se muito importante em dosagens futuras a observação da influência causada pela utilização de cinza de caldeira industrial nas dosagens com relação a essa propriedade do concreto.

O desempenho de resistência a compressão dos concretos dosados com cinza de caldeira industrial mostrou-se semelhante independente das variações do teor de substituição do agregado. Porém houve decréscimo dessa propriedade em relação ao traço padrão, ou seja, sem a utilização do resíduo. Portanto deve-se considerar essa redução de resistência em dosagens futuras, quando se tratar de comparações com dosagens sem a utilização do resíduo.

Concluiu-se, portanto, que a utilização da cinza de caldeira industrial na dosagem de concreto estrutural é viável, pois foram alcançadas características satisfatórias com relação a trabalhabilidade e desempenho de resistência a compressão conforme parâmetros normativos. Portanto, através desse estudo, foi possível identificar comportamentos iniciais do concreto dosado com cinza de caldeira e comprovar a viabilidade de utilização desse resíduo.

Entende-se que será necessária a continuidade das pesquisas para aprimoramentos, garantindo o bom desempenho do concreto no estado fresco e endurecido, bem como durante a vida útil das edificações. 


\section{REFERÊNCIAS}

Associação brasileira de normas técnicas. NBR 11579: Cimento Portland Determinação do índice de finura por meio da peneira 75 um (nํ 200). Rio de Janeiro, 2012.

Associação brasileira de normas técnicas. NBR 15823-2: Concreto autoadensável: Parte 2 - Determinação do espalhamento, do tempo de escoamento e do índice de estabilidade visual - Método do cone de Abrams. Rio de Janeiro, 2017.

Associação brasileira de normas técnicas. NBR 16889: Concreto - determinação da consistência pelo abatimento do tronco de cone. Rio de Janeiro, 2020.

Associação brasileira de normas técnicas. NBR 5738: Concreto - procedimento para moldagem e cura de corpos de prova. Rio de Janeiro, 2016.

Associação brasileira de normas técnicas. NBR 5739: Concreto - ensaio de compressão em corpos de prova cilíndricos. Rio de Janeiro, 2018.

Associação brasileira de normas técnicas. NBR NM 248: Agregados - Determinação da composição granulométrica. Rio de Janeiro, 2003.

Associação brasileira de normas técnicas. NM 52: Agregados - Determinação da massa unitária e volume de vazios. Rio de Janeiro, 2009.

Associação brasileira de normas técnicas. NBR 9833: Concreto fresco Determinação da massa específica, do rendimento e do teor de ar pelo método gravimétrico. Rio de Janeiro, 2008.

Bauer, Luiz Alfredo Falcao. Materiais de construção. Rio de Janeiro: LTC, 2008.

Cavalcante, Zedequias Vieira. A Importância da Revolução Industrial no Mundo da tecnologia. Unicesumar. Maringá, 2011. Encontro Internacional de Produção

RC: 96589

Disponível em: https://www.nucleodoconhecimento.com.br/engenhariacivil/concreto-estrutural 
Científica. Disponível em: https://www.unicesumar.edu.br/epcc-2011/wpcontent/uploads/sites/86/2016/07/zedequias_vieira_cavalcante2.pdf. Acesso em: 10 abr. 2021.

Ganzala, Gabryelly Godois. A Industrialização, impactos ambientais e a necessidade de desenvolvimento de políticas ambientais sustentáveis no século XXI. 2018. Centro Universitário Internacional - UNINTER. Disponível em: https://repositorio.uninter.com/bitstream/handle/1/295/1355104\%20\%20GABRYELLY\%20GODOIS\%20GANZALA.pdf?sequence=1\&isAllowed=y. Acesso em: 4 abr. 2021.

MEHTA, P. K. e MONTEIRO, P. J. M. Concreto: Estrutura, Propriedades e Materiais. São Paulo: Editora Pini, 1994.

Neville, Adam Matthew. Propriedades do concreto. São Paulo: Editora Pini, 1997.

Enviado: Agosto, 2021.

Agosto: Setembro, 2021. 